\title{
CALORIMETRIC STUDY OF THE ENDOGENOUS METABOLISM OF YEAST
}

\author{
KAZUKO NUNOMURA AND TERUYUKI FUJITA \\ The Institute of Applied Microbiology, University of Tokyo, \\ Bunkyo-ku, Tokyo 113
}

(Received April 20, 1981)

\begin{abstract}
A considerable amount of heat was produced when a suspension of yeast was added to a suspending medium in the absence of an exogenous energy source. The amount of heat produced was proportional to the cell concentration and accompanied by oxygen consumption, suggesting that the exothermic reaction may be due to the endogenous metabolism of cells. The patterns of heat production varied with the physiological state of cells, which were influenced by several factors including culture conditions, methods of storage, starvation, temperature and the suspending medium used for calorimetric measurements.
\end{abstract}

Calorimetric studies on microorganisms have been carried out by several groups and their application has now been extended into various fields. Regarding yeast, the thermal properties of metabolism and growth have been reported by several authors (1-8). Previously, the present authors made thermal studies on yeast growth using a twin-type rotatory calorimeter specially designed for microbiological uses (9). However, the details of the individual processes involved remain unsolved.

Preliminary experiments showed that a considerable amount of heat was produced when washed cells of yeast were added to a buffer solution without an external energy source (10). Many reports have mentioned high activity in the endogenous metabolism of yeast as one of the characteristics of the organism. Endogenous metabolism is a subject of deep interest and its properties must be elucidated to some extent in order to make the thermodynamic analysis of yeast metabolism and growth. The endogenous metabolism of yeast is readily observed by measuring oxygen consumption, but it is difficult to carry out an experiment of long duration using a manometer or oxygen electrode. On the other hand, calorimetry is a simple and convenient technique for measuring slow and long-lasting processes of microbial cells. Only a small amount of calorimetric data is available on the endogenous metabolism of yeast. RUBNER (11) was the first to describe direct calorimeteric data. Later, HOOGERHEIDE (12) observed by flow calorimetry 
the amount of heat produced by anaerobic and aerobic endogenous metabolism. LAMPRECHT (13) recently made a full review of what is known on yeast growth and metabolism in his excellent monograph.

This paper describes a calorimetric study of yeast cells under non-growing conditions for the purpose of elucidating the nature of endogenous metabolism.

\section{MATERIALS AND METHODS}

Organisms and cultivation. The yeasts studied were Saccharomyces cerevisiae IAM 4171, Saccharomyces carlsbergensis IAM 4727, Candida utilis IAM 4961, Baker's yeast and active dry yeast obtained from Oriental Yeast Co., Ltd., Tokyo, and a respiratory-deficient strain with its parent strain kindly provided by Dr. T. Gunge (Mitsubishi Chem. Ind. Res. Lab). All organisms were maintained on agar slant of malt extract medium.

Solid cultures were incubated on Wickerham's malt extract agar slant (14) at $30^{\circ}$ for $48 \mathrm{hr}$, while liquid cultures were incubated in a liquid medium of the same composition or in Hinshelwood's synthetic medium (15) with reciprocal shaking at $30^{\circ}$ for $17 \mathrm{hr}$. After incubation, cells were harvested and washed three times with distilled water, the final centrifugation pellet being dehydrated by the use of an unglazed plate. Unless otherwise noted, experiments were carried out with the washed cells thus prepared freshly suspended in $1 / 15 \mathrm{M}$ potassium phosphate buffer (pH 5.8).

Calorimetry. The calorimeter and experimental procedure used have been described elsewhere in detail $(9,10)$. The apparatus used was a rotation calorimeter of the conduction type with a maximal sensitivity of $2.5 \mu \mathrm{W}$; the time constant of its response was $8 \mathrm{~min}$.

The reaction vessel with a capacity of $40 \mathrm{ml}$, made by Pyrex glass, consisted of two compartments separated by a partition wall. One compartment was charged with $0.5 \mathrm{ml}$ of the cell suspension usually containing $24 \mathrm{mg}$ wet weight cells, while the other was charged with $4.5 \mathrm{ml}$ of buffer solution. Equal quantities of buffer solution were charged into each compartment of the reference vessel and a pair of reaction and reference vessels were set in the calorimeter. The reaction was started by rotating the calorimeter after the sample attained thermal equilibrium. Experiments were performed usually under aerobic conditions using an aeration assembly through which moist air was passed via cotton plugs. For anaerobic experiments, both vessels were gassed out for 10 min with nitrogen and tightly sealed before setting in the calorimeter.

The patterns of thermal events thus obtained have been called "thermograms." However, the word "power-time curves" will be used in this paper in accordance with the recommendation of IUPAC-IUB-IUPAB 1979. 


\section{RESULT}

\section{Effect of cell concentration}

Figure 1 shows the power-time curves and the amount of heat produced at various cell concentrations. The amount of heat was proportional to the cell concentration, suggesting that this heat production was related to the metabolism of the reserve energy source in the cells.
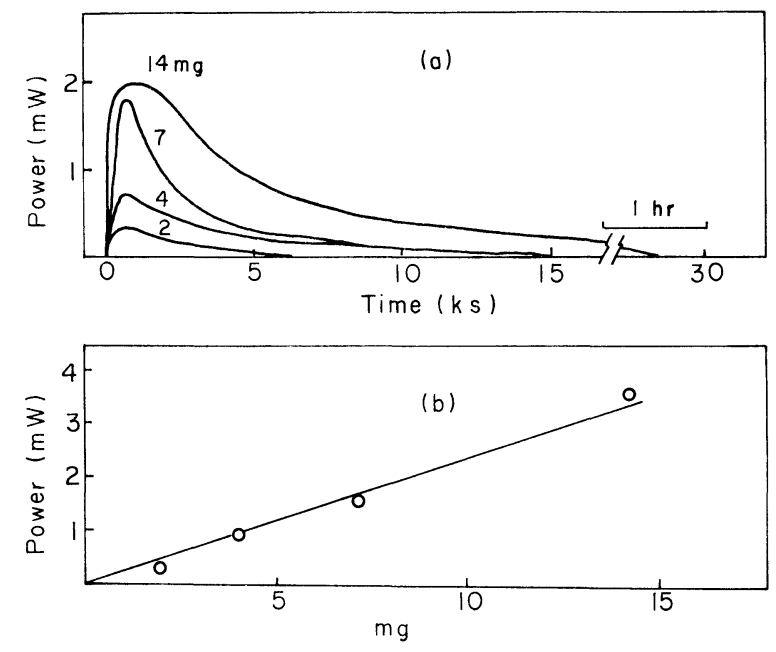

Fig. 1. (a) Effect of the cell concentration on power-time curves for endogenous metabolism; (b) the relationship between the cell concentration and the total amount of heat produced.

Figures indicate cell concentrations expressed in dry weight.

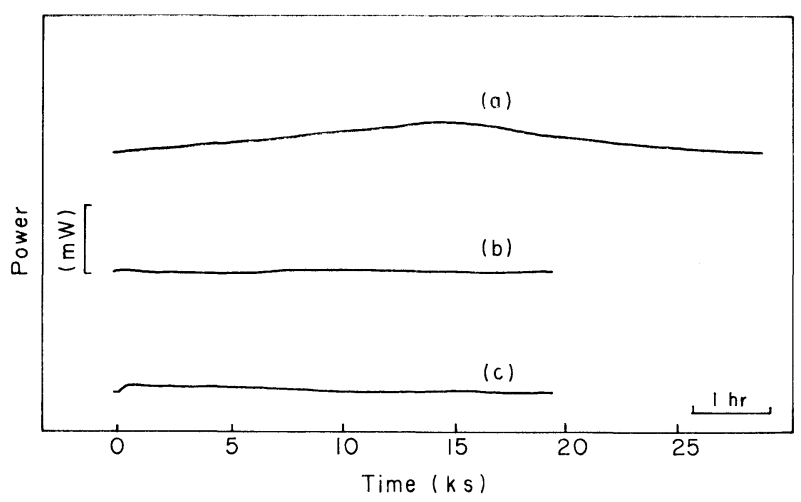

Fig. 2. Influence of $\mathrm{O}_{2}$ on power-time curves for endogenous metabolism.

(a) The air in the gas phase in the vessel was exchanged by passing $\mathrm{N}_{2}$ for $10 \mathrm{~min}$; (b) the air in both the gas and liquid phases in the vessel was completely excluded; (c) a power-time curve with cells of respiratory-deficient mutant, under an aerobic condition. 


\section{Effect of oxygen}

Experiments with the respiration-deficient mutant and those under anaerobic conditions showed no detectable heat production, as seen in Fig. 2, curves (b) and (c). This indicates that the observed heat production was caused by endogenous respiration. Curve (a) in Fig. 2 indicates the inadequacy of the simple method of gas exchange stated in the legend.

\section{Effect of culture condition}

Figure 3 shows the heat production of yeast cells obtained by use of different culture methods together with the starved cells. Heat production was hardly observed with the yeast cells starved for $20 \mathrm{hr}$ in a phosphate-buffer. The peak of the power-time curve with the cells obtained from liquid media was somewhat smaller than that obtained from solid media. This may be due to the difference in activity of the samples. The peak of the curve obtained with the cells cultured in the malt extract medium was high and narrow compared with that obtained by using synthetic medium and also, there were small differences in shape between the samples obtained under various culture conditions. The sharpness of the peaks of the curves decreased in the order of the cells harvested from stationary phase in liquid medium, stationary phase on solid medium and those at log phase. From these results, it seems probable that the shape of the power-time curve depends on the metabolic activity and amount of energy source reserved in yeast cells.

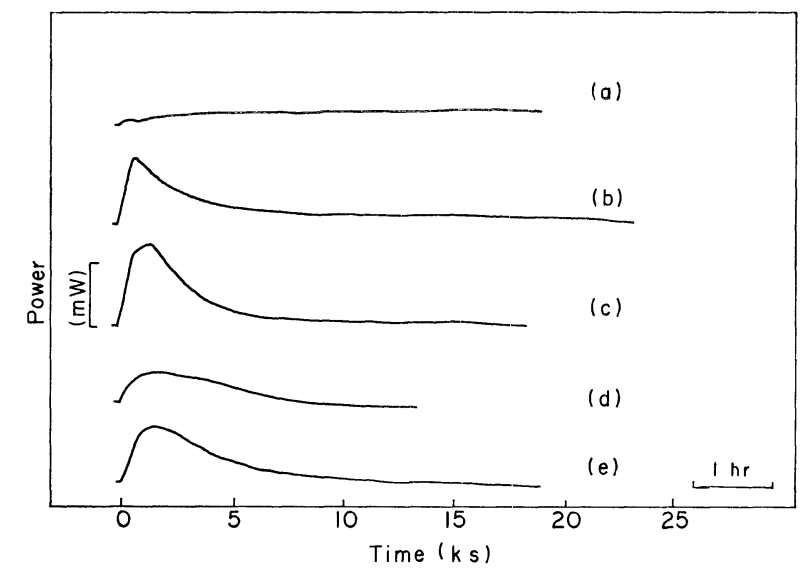

Fig. 3. Effect of culture conditions and starvation on power-time curves for endogenous metabolism.

(a) With cells cultured for $17 \mathrm{hr}$ in the liquid malt extract medium, harvested and washed three times, then shaken for $20 \mathrm{hr}$ at $30^{\circ}$ in a phosphate buffer; (b) with cells cultured in the liquid malt extract medium for $17 \mathrm{hr}$; (c) with cells cultured on the agar slant of malt extract medium for $48 \mathrm{hr}$; (d) with cells cultured in the synthetic liquid medium for $17 \mathrm{hr}$; (e) with cells cultured in the liquid malt extract medium for $6 \mathrm{hr}$. 


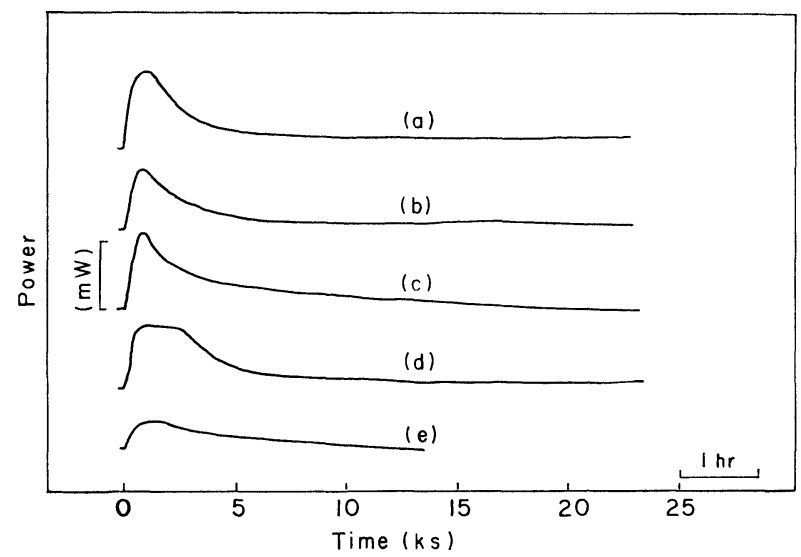

Fig. 4. Variation of power-time curves with different yeast strains.

(a) Saccharomyces carlsbergensis IAM 4727; (b) Saccharomyces cerevisiae IAM 4171; (c) Baker's yeast (Oriental); (d) ADY (Oriental); (e) Candida utilis IAM 4961. (a)-(c) and (e) were cultured in liquid malt extract medium for $17 \mathrm{hr}$; (d) was commercially available as granular "active dry yeast" which was rehydrated before use and suspended in a phosphate buffer.

Variation of heat production with different yeast strains

Figure 4 shows the power-time curve of different species of Saccharomyces together with the same curve for Candida utilis. Similar peak patterns were observed; however, heat production of $S$. carlsbergensis was somewhat larger than that of $S$. cerevisiae. ADY (commercially available as "active dry yeast") showed a longer period of initial heat production as compared with other samples. Candida utilis yielded a smaller amount of heat production as compared with Saccharomyces, as seen in (e).

\section{Effect of temperature}

The effect of temperature is shown in Fig. 5. It seems that the rate of heat production decreases gradually from $40^{\circ}$ to $20^{\circ}$ and steeply below $20^{\circ}$, suggesting some drastic changes in metabolic activity might take place around this temperature range. In our preliminary experiments similar effects of temperature were observed on the heat production resulting from the uptake of glucose by Saccharomyces cerevisiae. It seems probable that a decrease in certain cellular activity involved in the glycolysis pathway is responsible for the remarkable decrease in heat production below $20^{\circ}$.

\section{Effect of $p H$ value of suspending medium}

Figure 6 shows the effect of $\mathrm{pH}$ values of suspending media on the heat production of yeast cells. The shape of power-time curves and the total amounts of heat produced varied under different conditions. The difference in the heat pro- 

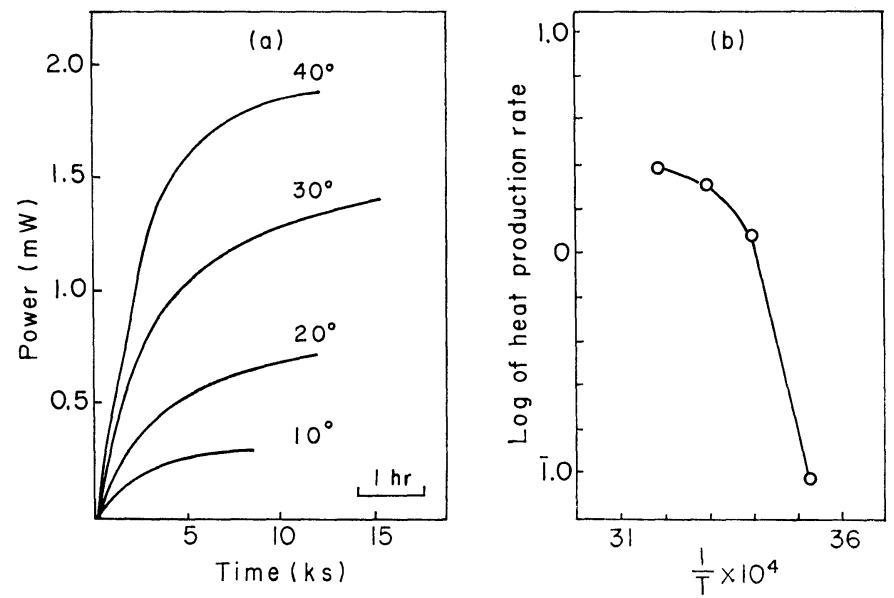

Fig. 5. Effect of temperature on power-time curves.

(a) Time courses of heat production at different temperatures; (b) relationship between logarithms of heat production rate and reciprocals of the absolute temperature.

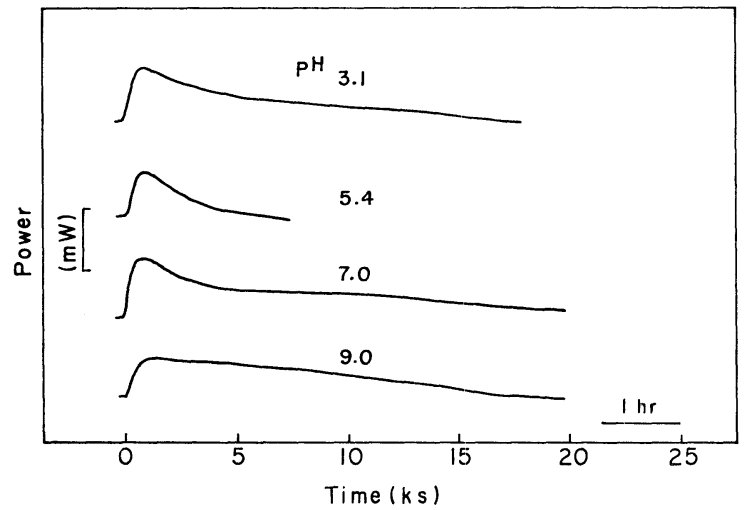

Fig. 6. Effect of $\mathrm{pH}$ values of the suspending medium on power-time curves.

In this experiment $200 \mathrm{~mm}$ tris-citrate buffer solution was used to maintain steady pH during the study period.

duction may depend on several types of reaction of the suspending medium with the yeast cells, namely the interaction with ionogenic groups on the cell surface which have ion-exchange properties (unpublished results) and the inhibition or temporary stimulation of endogenous metalolisms caused by "dilution."

\section{DISCUSSION}

The existence of endogenous metabolism at a level detectable by calorimetry may be a common property of microorganisms. Many aerobic organisms have 
been shown to exhibit endogenous respiratory activity, while similar endogenous heat production has been detected in anaerobic suspensions of Streptococcus faecalis by FORREST and WALKER (16). The original aim to study both aerobic and anaerobic metabolisms was not achieved because the greater heat effect of aerobic processes masked that of anaerobic ones at the same calorimetly sensitivity.

The power-time curve of yeast is a record of the rate of heat production. The chart area under the curve is proportional to the amount of heat produced. The average value of enthalpy change for endogenous metabolism obtained from Fig. 1 is $719 \mathrm{~J}$ per $\mathrm{g}$ dry weight of cells. Compared with the heat of combustion of glucose, this figure is equivalent to $45.7 \mathrm{mg}$ glucose. If it is assumed that all the material used for endogenous metabolism is glucose, the amount of glucose calculated from calorimetry corresponds to $4.5 \%$ of the dry weight of yeast cells. As washed cells of yeast have a higher level of endogenous metabolism than bacteria, special attention should be paid to this heat production when interpreting the initial part of the power-time curve in calorimetry. The magnitude of the heat production of endogenous metabolism is generally related to the cell concentration, the rate of metabolism per unit mass, the enthalpy change of reaction and the amount of reserve materials. In this study the authors are mainly concerned with the results obtained during the initial several hours, because after this period the heat production decreases gradually and it is difficult to determine the exact time of its termination.

The rapid heat production is possibly due to the initial response of the cell to changes in environmental conditions to adjust their rate of endogenous metabolism. This reaction seems to be analogous to the heat of dilution reported by FORREST and WALKer (16) with $S$. faecalis and the "agitation/dilution phenomenon" by Ross et al. (17) with blood platelets.

Cells grown exponentially or in synthetic medium show smaller and broader peaks (Fig. 3). This fact indicates that the previous growth history of the cells was of importance in allowing the laying down of reserved materials that could later be degraded during endogenous metabolism. The peak for cells obtained from solid culture is broader than that from liquid culture; this may relate to the homogeneity of cellular activity and amount of reserved materials.

It is interesting to note that there is a critical range of temperature in endogenous metabolism, and this may give a clue to the detailed characterization of the metabolism.

Further study is necessary to define the metabolic source and mechanism of the heat production, but results obtained in this paper indicate that calorimetry gives some information about the endogenous metabolism and can be applied to other processes of biological interest.

\section{REFERENCES}

1) E. H. Battery, Physiol. Plant., 13, 628 (1960).

2) J. P. Belaich, J. C. Senez, and M. Murgier, J. Bacteriol., 95, 1750 (1968). 
3) M. Murgier and J. P. Belaich, J. Bacteriol., 105, 573 (1971).

4) I. Lamprecht, B. Schaarschmidt, and W. Stein, Biophysik, 10, 177 (1973).

5) A. E. Beezer, R. D. Newell, and H. J. V. Tyrrell, J. Appl. Bacteriol., 41, 197 (1976).

6) B. SchaARSChmidt and I. LAmprecht, Rad. Environ. Biophys., 14, 153 (1977).

7) A. E. Beezer, In Applications of Calorimetry in Life Sciences, ed. by I. LAmprecht and B. SchaARSCHMidt, Walter de Gruyter, New York (1977), p. 109.

8) B. F. Pery, A. E. Beezer, and R. J. Miles, J. Appl. Bacteriol., 47, 527 (1979).

9) T. Fujita, K. Nunomura, I. Kagami, and Y. Nishikawa, J. Gen. Appl. Microbiol., 22, 43 (1976).

10) T. Fujita and K. Nunomura, In Application of Calorimetry in Life Science, ed. by I. LAMPrecht and B. SchaARSChmidt, Walter de Gruyter, New York (1979), p. 119.

11) M. Rubner, Arch. Hyg., 57, 244 (1906).

12) J. C. Hoogerheide, In Proc. Fourth Int. Symp. Yeasts, Vienna, ed. by H. Klaushofer and U. B. Sleyter, Univ. of Agric., Wien (1974), Part 1, A9, 17.

13) I. Lamprecht, In Biological Microcalorimetry, ed. by A. E. Beezer, Academic Press, New York (1980), p. 43.

14) L. J. Wickerham, U. S. Dept. Agric. Tech. Bull., No. 1029 (1951).

15) B. C. Kilkenny and S. C. Hinshelwood, Proc. Roy. Soc. B, London, 138, 375 (1951).

16) W. W. Forrest and D. J. Walker, Biochem. Biophys. Res. Commun., 13, 217 (1963).

17) P. D. Ross, A. P. Fletcher, and G. A. Jamieson, Biochim. Biophys. Acta, 313, 106 (1973). 